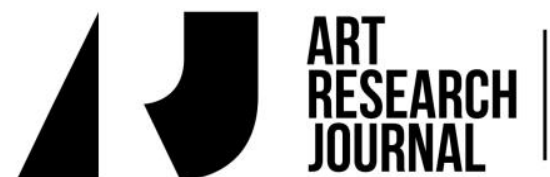 \\ Art Research Journal / Revista de Pesquisa em Arte ABRACE, ANPAP e ANPPOM em parceria com a UFRN
}

\section{Wolfgang RIHM - Dionysos: uma escrita dos espaços interiores ${ }^{1}$}

Ivanka Stoianova Université de Paris 8

\author{
(a Georges Blœss)
}

A «fantasia operística» / «Opernphantasie» Dionysos - «cenas e ditirambos a partir de textos de Friedrich Nietzsche» para solistas, coro e orquestra (RIHM, 2009-2010) - do compositor alemão Wolfgang Rihm² (1953-) teve sua estréia mundial em 27 jul. 2010, dentro da programação do festival de Salzbourg, sob a direção artística e regência de Ingo Metzmacher, com direção cênica de Pierre Audi e cenários de Jonathan Meese. Esta obra capital no enorme catálogo de Rihm sucede suas duas óperas de câmera Faust und Yorick (1976), a partir de texto de J. Tardieu, e Jakob Lenz (1977-78), a partir da novela homônima de G. Büchner; o «poema dançado» Tutuguri (1980-82), inspirado em A. Artaud; e as obras destinadas à cena de ópera Fdipus (1986-87), com textos de Sófocles, Hölderlin, Nietzsche e H. Müller e Die Eroberung von Mexiko / A Conquista do México (1987-91), com textos de A. Artaud, O. Paz e cantos mexicanos antigos.

\section{Uma não-narrativa}

Dionysos não é uma ópera no sentido tradicional do termo, pois renuncia completamente à narrativa e a toda evolução direcional dos eventos cênicos. Trata-se de uma não-narrativa aberta, uma fantasia plural de música-teatro em

\footnotetext{
1 Tradução do francês por Guilherme Sauerbronn.

2 Wolfgang Rihm nasceu em 1952 em Karlsruhe, onde mora. Estudou composição com K. Stockhausen, KI. Huber, W. Fortner e H. Searle. Autor extremamente prolífico, W. Rihm compôs dezenas de obras instrumentais e vocais-instrumentais, para grupos de câmera, orquestra sinfônica, óperas. Desde 1985 é professor de composição na Escola Superior de Música em Karlsruhe. Suas obras são publicadas pela Edições Universal, Viena.
} 
várias dimensões, constituída de «cenas e ditirambos» em «quatro planos» ou «lugares»3: Um mar, Na montanha, Espaços interiores 1-3, Um lugar. Trata-se de cenas musicais abertas, que remetem aos momentos importantes da vida de Nietzsche, mas, acima de tudo, às idéias universais de sua filosofia: as relações homem - mulher, masculino - feminino, apolíneo - dionisíaco, divino - humano, indivíduo - massa, vida - morte etc. Daí a possibilidade de impacto sobre todo o público interessado no teatro musical contemporâneo. ${ }^{4}$

A estratégia composicional em Dionysos se situa na linhagem das Abgesangszenen (1979-1981) de Rihm, nas quais já podemos observar a interação sinfônica de peças orquestrais e de peças cantadas (também sobre textos de Nietzsche) numa espécie de gênero misto onde interagem o Lied sinfônico, a cena de ópera e a peça para orquestra sinfônica ${ }^{5}$. As «cenas» em Dionysos correspondem aos componentes delimitados na dramaturgia do espetáculo músico-teatral. Ao passo que os «ditirambos» são os momentos de reflexão coral com suporte orquestral denso. Na Grécia antiga, o ditirambo era um gênero da prática coral dos hinos glorificando o deus Dioniso. Os poemas de Nietzsche intitulados Dionysos Dithyramben / Ditirambos de Dioniso pouco têm a ver com o gênero antigo da poesia hínica e remetem muito sucintamente ao deus grego. Apenas o poema Die Klage der Ariadne / A lamentação de Ariadne e alguns elementos temáticos - a idéia do labirinto e a idéia da laceração (que Rihm associará aos personagens de Apolo e Marsyas) - fazem alusão aos mitos ligados a Dioniso. Os Dithyramben / Ditirambos na obra de Rihm são comentários corais cuja função é comparável àquela dos poemas nos escritos filosóficos de Nietzsche.

A primeira cena, bastante longa, ou mais precisamente o primeiro quadro - Um mar - e a breve quarta e última cena - Um lugar - repousam sobre seqüências dramatúrgicas explícitas, porém muito concisas, que se organizam em quadros ou momentos musicais bastante estáticos, fixos, mas poderosamente ativos:

\footnotetext{
${ }^{3}$ Dizia-se "mansão" na Idade Média para definir um lugar do teatro onde se passava uma cena.

${ }^{4}$ Nota da editora: No Youtube é possível encontrar pequenos trechos de Dionysos, incluindo um breve comentário de Rihm na divulgação do DVD gravado na estreia no Salzburger Festspiele (2010). Disponível em: https://www.youtube.com/watch?v=jg1dfxvMasA. Acesso em: 24 abr. 2015.

${ }^{5}$ Cf. RIHM, W. "Einige Gedanken zur Karlsruher Uraufführung der Zweiten Abgesangsszene". In RIHM, W. Ausgesprochen, Schriften und Gespräche, Band 2, Winterhur: Amadeus, 1997, p. 316319.
} 
No primeiro quadro, Ariadne implora por seu salvador ou seu deuscarrasco Dioniso, numa alusão à "luta" de Nietzsche por Cosima (lembremos que nas cartas tardias endereçadas a Cosima Wagner, por quem se apaixonara, Nietzsche a chamava "Ariadne" e assinava "Dioniso");

O último quadro representa o célebre episódio da vida de Nietzsche, pouco antes do seu trágico colapso psíquico: em Turim, no ano de 1889, ao avistar um cocheiro chicoteando cruelmente seu cavalo, Nietzsche, comovido, se ajoelha diante do animal, envolve ternamente seu pescoço com seus braços e o beija, chorando, tomado de indizível compaixão.

A segunda cena - Na montanha - representa a relação complementar e atormentada entre N. - Nietzsche (mas também Niemand / qualquer um ou ninguém) e Ein Gast / Um hóspede, seu duplo, que alcança o sucesso exatamente onde $\mathrm{N}$. falha.

A terceira cena é a mais densa, a mais movimentada, com um verdadeiro desenvolvimento teatral de eventos nas três partes que a constituem:

A primeira, intitulada Innenraum 1 / Espaço interior 1 apresenta o encontro dos dois personagens - N. e Um hóspede - vagando entre os homens, ambos em busca do amor;

A segunda parte - Innenraum 2 / Espaço interior 2 - se desenvolve no interior de um bordel: os dois homens - N. e Um hóspede - se confrontam na busca de sua própria verdade. Neste momento escutamos o Lied do Wanderer / o Lied do Viajante, aquele que erra através do mundo sem jamais encontrar a paz. N. acaba sendo atado por Ariadne, enquanto Um hóspede é dilacerado pelas mulheres, que se chamam todas Esmeralda;

A terceira parte - Innenraum 3 / Espaço interior 3 - apresenta N. que se recolhe mais e mais em sua vida interior até o ponto em que o deus Apolo Ihe arranca a pele, como fizera em outra ocasião, segundo a lenda, com seu concorrente, o flautista Marsyas, muito superior a ele na arte dos sons. Escoriado, esfolado vivo, N. sabe que é vítima da inveja e se obstina em continuar buscando o amor.

Apesar do fato de que a primeira e a última cena remetem de forma explícita aos elementos conhecidos da biografia de Nietzsche, todas as cenas - inclusive a Segunda, que "expõe" os dois personagens principais N. e Ein Gast, e, é claro, a Terceira com suas três seções - são acima de tudo a representação, sonora e cênica, dos espaços interiores do universo de Nietzsche onde cada um pode se 
reencontrar. Trata-se de representações músico-teatrais sob a forma de quadros ou de momentos estáticos, como na Primeira e na Quarta e última cena; ou de representações cênicas mais teatrais, em diálogo, como na Segunda cena ou, mais ainda, em três "espaços interiores", como na Terceira. Parece evidente que o compositor atribui muito mais importância não aos eventos cênicos exteriores, mas aos estados emocionais e aos movimentos dos afetos nos espaços interiores que se transmutam em teatro musical expressivo ${ }^{6}$.

A fantasia operística de Rihm é na realidade uma transcrição músico-cênica densa da experiência pessoal do compositor com as obras filosóficas e poéticas de Nietzsche, assim como com a personalidade excepcional do filósofo através de momentos-chave de sua biografia7. Em seu Dionysos, Rihm compõe seu próprio caminhar com Nietzsche, suas próprias viagens nos espaços interiores despertados no contato com o universo do filósofo. O desenvolvimento cênico em Rihm ignora toda narrativa tradicional de libreto operístico, todo desenvolvimento linear, em benefício de situações sonhadas que se submetem unicamente à lógica dramatúrgica relativamente livre da "fantasia operística"8.

A não-narrativa ou a anti-narrativa é constituída portanto de diferentes "espaços interiores" que ignoram a teleologia típica da ópera. Tais espaços emergem como campos de associações livres e pluridirecionais, submetidas unicamente à lógica do sonho, ou, dito de outra forma, segundo a lógica errática do Wanderer / do viajante sem destino certo ${ }^{9}$, que evoluem em aparições acústicas cada vez mais expressivas e cativantes. Trata-se de uma avalanche mais ou menos livre ou casual de idéias musicais, de momentos sonoros e cênicos, inspirados pela coletânea de poemas Dionysos-Dithyramben de Nietzsche, escrita pouco antes de seu colapso psíquico. Durante mais de trinta anos, Rihm conviveu com o projeto de Dionysos, a mitologia grega e a obra filosófica e poética de Nietzsche,

\footnotetext{
${ }^{6}$ Lembremos que já o primeiro quarteto de cordas de W. Rihm é intitulado "Im Innersten" / "No mais profundo, interior, íntimo" (1976).

7 Nietzsche é um dos autores preferidos de Rihm. Várias de suas obras repousam sobre textos de Nietzsche, dentre as quais sua Terceira sinfonia (1976) para soprano, barítono, coro misto e orquestra, sua segunda Abgesangsszene (1979) para voz e orquestra, sua Quarta Abgesangsszene (1979-80) para mezzo-soprano e orquestra, sua Quinta Abgesangsszene (1979-83) para mezzosoprano, barítono e orquestra, Klangbeschreibung 2 (1986-87) para 4 vozes, 5 cobres e 6 percussões.

8 A noção de fantasia na música instrumental na época do classicismo e do romantismo remete sempre a uma liberdade formal - lembremos das Fantasias para piano de Mozart. A noção de "fantasia operística" em Rihm é um neologismo que busca definir a especificidade da dramaturgia musical e cênica desta obra de "música-teatro".

${ }^{9}$ A tradução francesa para "excursionista", "viajante" ou "turista" é certamente imprecisa e muito pouco poética, em todo caso estranha ao espírito do romantismo.
} 
antes de chegar na sua "fantasia operística" que coloca em evidência o próprio movimento de seu pensamento em torno de Nietzsche, sem começo nem fim. $O$ próprio compositor é o "pensador em cena"10, vagueando pelo universo de Nietzsche. O processo composicional - Rihm escreve simultaneamente a música, o texto e os quadros cênicos - é uma invenção contínua da linguagem musical, que ignora as fronteiras convencionais. Não se trata, portanto, de um texto musicado, nem de música para acompanhar a dramaturgia cênica, mas de uma invenção permanente da linguagem múltipla e plurivalente, desdobrando-se no espaço e no tempo, confirmando, diríamos, a definição de Freud: "Sob a palavra linguagem, não se deve entender apenas a expressão do pensamento em palavras, mas também a linguagem gestual e todos os outros tipos de expressão da atividade psíquica, como escritura"11 - a própria escritura musical e mais especificamente aquela de Rihm com seus "espaços interiores".

\section{A relação com o texto}

Para suas obras de "Musik-Theater" / "Música-teatro"12, Rihm compõe sempre "uma música constituída de palavras, de ações, de sons, de imagens, de melodias, de ruídos, de luzes. Tudo o que aparece neste desenvolvimento é música."(RIHM, 2002, p.194) O impulso inicial que procede geralmente de um ou de mais texto(s) é particularmente importante. Em Dionysos são utilizados fragmentos provenientes dos Dionysos Dithyramben (1888-89) de Nietzsche (NIETSZCHE, 2010, p. 58-87), que ele recompõe e ordena livremente: "Minha base são os Dionysos Dithyramben de Nietzsche, no interior dos quais eu leio, por assim dizer, um texto - a partir dos quais eu deduzo um texto. Eu o exprimo do seguinte modo: o libreto é meu, mas cada palavra é de Nietzsche". (RIHM, 2010a). "Cada palavra cantada é de Nietzsche, e apesar disso o texto é meu". (RIHM, 2010b, p. 20).

\footnotetext{
10 Cf. SLOTERDIJK, P. Der Denker auf der Bühne / Nietzsches Materialismus, Frankfurt: Suhrkamp 1353, Neue Folge, Band 353, 1986.

${ }_{11}$ Cf. FREUD, S. "Das Interesse an der Psychoanalyse", Gesammelte Werke, Band VIII, S. 390.

$12 \mathrm{~A}$ noção de Rihm "Musik-Theater" não é equivalente à de "teatro musical", muito pouco precisa no contexto das pesquisas composicionais pós anos 60 do século $X X$, que originaram o teatro instrumental, o happening, os espetáculos multimídia de todo tipo, a ópera. A noção de Rihm insiste na multiplicidade dos materiais utilizados, liberados de toda narração direcional e tornandose todos música-teatro.
} 
Os nove poemas, que Nietzsche preparava para publicação no fim de 1888, mas que não puderam ser publicados por ele em função do súbito agravamento de sua doença mental, são constituídos de textos-fragmentos: alguns, já publicados em Also sprach Zarathustra / Assim falava Zaratustra (1883-85), são transplantados aqui. Novos textos lhe são acrescentados. É bem sabido que, desde sua juventude, Nietzsche escrevia poemas: a arte poética é um aspecto essencial de sua produção literária e uma parte constitutiva de seus escritos filosóficos. Em A Gaia Ciência, Para Além do Bem e do Mal, Nietzsche contra Wagner, o filósofo incluiu poemas. Sua obra mais conhecida, Assim falava Zaratustra, abole de forma explícita as fronteiras entre linguagem filosófica e linguagem poética. O laço estreito e a fusão orgânica de poesia e filosofia em Nietzsche exercem uma influência insuspeitada sobre o modo de pensar do compositor Rihm. Exemplos convincentes neste sentido são a interação orgânica do Lied para voz e piano Der Wanderer, escrito por Rihm sobre o poema homônimo de Nietzsche alguns anos antes, e o contexto músico-teatral de Dionysos (30 quadro, Innenraum 2) (RIHM, 2009-2010, p. 234-241) com sua textura orquestral complexa ${ }^{13}$.

"Seu texto (os Dionysos-Dithyramben - IS) é uma compilação e eu o tomo como base, como fundo."14 (RIHM, 2010b, p. 20-21) Efetivamente, podemos compreender a fantasia operística Dionysos como reescritura múltipla, como Übermalung ${ }^{15}$ musical e cênica dos fragmentos poéticos de Nietzsche. Os Ditirambos de Dioniso do filósofo com sua grande arte poética (como em Nur Narr! Nurr Dichter! / Nada além de bufão! Nada além de poeta! ou Zwischen Raubvögeln / Entre as aves de rapina ou Klage der Ariadne / Lamentação de Ariadne $\left.{ }^{16}\right)$, mas ainda com seu gosto por vezes duvidoso, são considerados por Rihm como "perfeitamente apropriados para a música-teatro" (RIHM, 2010b, p. 21). Pois o texto fragmentário é por essência aberto e convida ao jogo com seus pedaços. A interação de fragmentos de texto permite um adensamento ou, ao

\footnotetext{
13 Lembremos que o mesmo poema - Der Wanderer - da época de Zaratustra de Nietzsche, é utilizado na última peça do ciclo de Schoenberg Acht Lieder für Gesang und Klavier Op. 6 / Oito Lieder para canto e piano Op. 6 (1903-05). Em 2001 Rihm escreve seus Sechs Gedichte von Fr. Nietzsche / Seis poemas de Fr. Nietzsche para barítono e piano: Der Einsamste, Der Herbst, Der Wanderer (I), Der Wanderer (II), "Der Wanderer und sein Schatten", Venedig.

${ }^{14}$ Grundierung - uma primeira camada de pintura.

15 Übermalung - é a pintura sobre outra pintura. Lembremos que o mestre a Übermalung, o pintor austríaco Arnulf Rainer é um dos artistas preferidos de W. Rihm.

${ }^{16}$ O texto de Klage der Ariadne já fora utilizado por Rihm em sua obra Drei Frauen (2001-2009), teatro musical em três monodramas e dois interlúdios.
} 
contrário, uma rarefação dos níveis de sentido que se completam mutuamente ${ }^{17}$ (Ibid). E este jogo que permanece aberto, mas nunca abandonado à própria sorte, chama a música, torna necessária sua intervenção com sua capacidade específica de produzir sentido.

O compositor utiliza relativamente pouco o texto, geralmente fragmentos particularmente densos e carregados de sentido que ele repete, como "Mich willst Du?" / "É a mim que tu queres?" ou "Ich bin dein Layrinth" / "Sou teu labirinto" na Primeira cena; ou então "Gott als Schaff" / "Deus como cordeiro", "lachen" / "rir", "Ich bin deine Wahrheit... Wahrheit... Wahrheit" / "Sou tua verdade... verdade... verdade" na Quarta cena.

É sabido que a repetição imediata de uma palavra ou de um fragmento de texto é o procedimento mais utilizado para a musicalização de um texto: ela permite desvelar musicalmente a sonoridade e o significado da palavra, a aura do texto, mas também uma situação precisa com a sensibilidade e a emoção para além da significação linguística precisa. É esse o caso na Primeira cena onde Ariadne repete várias vezes a N. "Sprich endlich! Sprich! Sprich!" / "Fala enfim! Fala! Fala!", mas a cada vez com fórmulas musicais e tipos de expressão diferentes: (flehend / suplicante, kehlig / gutural, dolce / docemente, furioso / furiosamente) (RIHM, 2009-2010, p. 13). Também na Primeira cena a repetição dos fragmentos textuais "Heisse Hände! Hände! Hände!" / "Mãos quentes! Mãos! Mãos!" gera uma linha melódica contínua altamente expressiva na parte de Ariadne (Ibid, p. 20) que se origina parcialmente da melodia "Ich bin Dein Labyrinth" / "Sou seu labirinto" em N. (Ibid., p. 44), mas numa versão descendente ${ }^{18}$. Na parte de Ein Gast / Um hóspede da Segunda cena, a repetição do texto "Sechs Einsamkeiten kennt er schon, Einsamkeiten..." / "Seis solidões ele já conhece, solidões..." gera a princípio um quase Recitativo, em seguida figuras melódicas silábicas. A repetição do texto "Meine Seele" / "Minha alma" com figuras melódicas diferentes nas partes de N. e de Ein Gast na Terceira cena (Innenraum 2) permite exprimir musicalmente as diferentes nuances dos afetos (Ibid., 2009-1010, p. 213-214 / 216-217). A repetição amplificada imediata pode ser utilizada como comentário musical, constituindo uma espécie de corpo de

\footnotetext{
17 "Está claro que eu jogo com textos que, como se diz, se completam às mil maravilhas. Como se eu tivesse pensado a respeito."

18 O procedimento lembra Die glückliche Hand / A Mão da sorte de Schoenberg, onde o leitmotiv do homem é uma figura melódica ascendente (violoncelos), enquanto que o leitmotiv da mulher é uma melodia descendente (violino solo).
} 
ressonância e expansão no tempo que amplifica uma situação ou uma emoção. É o caso na música dos três delfins (três vozes femininas) na Primeira cena: elas cantam inicialmente sobre vogais sem palavras, em seguida continuam em "lá lá - lá" "beschwörend zu Ariadne hin" / "implorando por Ariadne", para chegar à palavra carregada de sentido "Labyrinth", repetida diversas vezes em fórmulas melódicas expressivas. (Ibid., p. 52-54) A repetição do tipo hoquetus ${ }^{19}$ com aceleração e crescendo é utilizada como forma de elevar a tensão, como é o caso na confrontação de N. e Ein Gast na Segunda cena com o texto "Jetzt, jetzt, Selbstkenner, Selbsthenker" / "Agora, agora, conhecedor de si, carrasco de si". "Sie geraten ausser sich - ein Höhenrausch?" / "Eles ficam fora de si - uma embriaguez das alturas?", escreve Rihm nas marcações da cena. A repetição do tipo hoquetus evolui para uma música em ostinato / em figuras obstinadas onde são repetidas inúmeras vezes e cada vez mais rápido dois compassos com o mesmo texto "Selbstkenner, Selbsthenker" proveniente de Die Klage der Ariadne / A lamentação de Ariadne.

A repetição amplificada à distância no tempo é um procedimento eficaz de direcionalidade no desenvolvimento musical-cênico, de crescendo emocional com forte impacto. Assim: "Sprich!", "Sprich endlich!" / "Fala!", "Fala enfim!" na parte de Ariadne na Primeira cena aparece diversas vezes em ocorrências temporalmente distantes, em versões musicais muito diferentes - quase gritado, cantado sílaba por sílaba, falado, cantado com grandes saltos intervalares etc. o que confere à cena uma tensão e expectativa crescentes.

A repetição amplificada a grandes distâncias traz conseqüências semânticas consideráveis, organizando a obra enquanto totalidade. Ao final da Terceira cena (Innenraum 3), escutamos de N. em um contexto músico-cênico completamente diferente as palavras de Ariadne da Primeira cena: "Mein Unbekannter, mein Henker, Gott" / "Meu desconhecido, meu carrasco, deus", "Schamloser Unbekannter du Henker Gott" / "Desconhecido desavergonhado, tu, carrasco deus", "Wer wärmt mich, wer liebt mich?" / "Quem me aquece, quem me ama?" em N. na Terceira cena e "Wer wärmt mich, wer liebt mich?", "Oh kommt zurück, mein Unbekannter Gott, mein Schmerz, mein letztes Glück!" / "Oh volte, meu

19 Hoquetus: o hoqueto é um procedimento rítmico que consiste em repartir uma a uma entre muitas vozes os sons de uma mesma linha melódica. 
deus desconhecido, minha dor, minha derradeira alegria!" na parte de Ariadne da Primeira cena20.

O compositor pode também renunciar completamente à palavra. Assim, na Primeira cena, são utilizados vocalizes não verbais na parte de Ariadne: "Ela canta desesperada em direção a N." / "Sie singt N. verzweifelt an", enquanto que "ele continua a remar e permanece 'ausente', mergulhado em si próprio" / "er hält im Rudern inne und bleibt 'abwesend' in sich zusammengesunken". N. permanece mudo por muito tempo, depois realiza diversas tentativas balbuciando penosamente, para pronunciar enfim a frase de Dioniso provinda do poema Klage der Ariadne / A lamentação de Ariadne "Ich bin dein Labyrinth" / "Sou teu labirinto".

A música vocal sem palavra é freqüentemente utilizada como comentário musical ou desdobramento espacial do significado lingüístico: lembremos o canto não verbal dos três delfins (três vozes femininas) endereçado a Ariadne na Primeira cena. Na Terceira cena (Innenraum 3) onde N. é maltratado por Apolo, ouvimos o canto plangente sem palavras do coro das ninfas ou das mênades (RIHM, 2009-2010, p. 332-337). Enfim, nos seis últimos compassos da fantasia operística, ouvimos novamente os vocalizes não verbais das duas soprani coloratura, como reminiscência distante do feminino.

É precisamente o texto fragmentário que torna necessário um desdobramento musical e cênico multidimensional. "Estes textos chamam a música. Eles não são alta poesia. Os traços humanos do comércio com sua matéria Ihes são inerentes. E ali, a música pode novamente entrar em jogo."21 (RIHM, 1997, p.319) E mais ainda, é ali que pode naturalmente entrar em jogo a música-teatro da fantasia operística.

\section{As personagens}

As personagens da obra de Rihm pouco se assemelham às personagens habituais de ópera. Se as cenas ou quadros são "os recipientes" (Rihm) dos múltiplos desenvolvimentos músico-cênicos, as personagens são espaços flexíveis,

${ }^{20}$ Cf.RIHM, 2009-2010, Terceira cena - p. 324, 340-343 e Primeira cena - p. 18-23, 58-59.

21 "Diese Texte lassen Musik zu. Sie sind nicht bereits Musik gewordene Lyrik. Die menschlichen Spuren der Auseinandersetzung mit ihrem Stoff haften ihnen an. Daran kann wiederum Musik ansetzen." 
moventes, variáveis, desempenhando papéis plurais e em constante transformação. As fronteiras entre as personagens tornaram-se permeáveis e ainda assim podemos reconhecer facilmente os papéis principais, que preservam sua integridade em todas as circunstâncias.

N. é, evidentemente, Nietzsche, mas também Dioniso, o dionisíaco em Nietzsche e, em geral, o filósofo dionisíaco, o artista, o errante, Marsyas, a Pele, Nescitur, Nobody e Everybody, isto é, também eu e você.

Ein Gast, é o duplo de N., seu aspecto apolíneo, o próprio Apolo, mas também o homem que maltrata o cavalo.

N. e Ein Gast são de fato dois aspectos, simultaneamente opostos e complementares do personagem principal N. Trata-se de um duplo esclarecimento musical-cênico - "Doppel-Belichtung" (RIHM, 2010c, p. 39) - do papel que se encontra teatralizado, multiplicado, espacializado, traduzido em música-teatro. O monólogo interno - isto é, o movimento do pensamento, o rumo do processo mental que, mesmo interiorizado, é sempre um assunto do corpo, como Nietzsche sempre buscou provar em sua filosofia - é apresentado sob a forma de diálogo e, desse modo, exteriorizado, tornado audível e visível, posto em cena nas ações das personagens.

Ariadne - a bem amada abandonada - é o amor impossível, inatingível para N., o eterno feminino, a mulher, a mãe. Ela aparece também em Innenraum 2, no bordel da Terceira cena, e ainda no final da fantasia operística, após o quadro cênico de uma Pietà muito cristã onde N. (ou a Pele) cai nos braços de Ariadne Maria, sempre em busca de amor.

As ninfas da Primeira cena se transformam em delfins, depois em cortesãs, todas com o mesmo nome Esmeralda, e por fim em mênades - formas míticas na Terceira cena. Elas compõem a personagem fluida, fugidia, variável e inatingível da Mulher, da feminilidade, do feminino que buscam desesperadamente N. e Ein Gast.

As personagens emblemáticas perfeitamente despersonalizadas em Rihm agem como espaços proteiformes ${ }^{22}$ ou corpos de ressonância para conteúdos semânticos múltiplos. O desdobramento e a multiplicação dos personagens criam

\footnotetext{
22 Proteu é o deus do mar que herdara de seu pai Poseidon o dom da profecia e era capaz de assumir diferentes formas, segundo sua vontade.
} 
figuras espaciais, variáveis e pluridimensionais que são mais adaptadas ao fluxo associativo do pensamento ou do sonho do que aos papéis operísticos individualizados da ópera tradicional com seu desenvolvimento teleológico. Sabese que na euforia de seus distúrbios psíquicos, Nietzsche mudava freqüentemente suas máscaras, assim como seu modelo Dioniso: ele se enxergava ora como César, ora como Shakespeare, como Rei da Itália ou Richard Wagner. Em seus escritos filosóficos, as metamorfoses, as mutações, os desenvolvimentos não são raros: lembremo-nos de Assim falou Zaratustra, onde observamos a metamorfose do espírito em camelo, leão e criança. Cada cena em Rihm e cada faceta de suas figuras cênicas pertencem simultaneamente a diversos níveis da enunciação músico-cênica múltipla em Dionysos, este "drama imaginário em torno de N. que é um homem, que é Dioniso, que é o Crucificado, que é Marsyas, que é o Artista, que é..." - como explica o compositor.

Enquanto agregado aberto de muitos conteúdos semânticos, cada personagem, ou melhor, cada figura cênica em Rihm é composta segundo os princípios fundamentais das artes temporais: "o princípio da ação múltipla e concentrada" e o princípio da "interação das funções" 23 : conforme o primeiro, um objetivo estético é alcançado através de múltiplos e variados meios; conforme o segundo, um mesmo meio é utilizado para servir a diversas finalidades. Os dois princípios contribuem para a construção de uma obra unificada e coerente, apesar da diversidade de seus componentes.

Segundo o primeiro princípio, diferentes personagens, aspectos, detalhes, facetas respondem ao mesmo objetivo unificador: assim N., Ein Gast, der GottHenker / o Deus-carrasco, Dioniso, Marsyas, a Pele estão todos presentes, reunidos na figura, particularmente importante para Rihm, do Wanderer / o Errante que tem a vantagem de ser, para todo espectador, um personagem mais familiar do que o filósofo Nietzsche.

Em conformidade com o segundo princípio, meios expressivos específicos são utilizados para responder a objetivos artísticos diversos: assim, a vocalidade feminina, as vozes de mulheres e, mais precisamente, os soprani coloratura

\footnotetext{
${ }^{23}$ A teoria estética que desenvolveu nos anos 1940-70 estes princípios essenciais em musicologia teórica, sobre a base da tradição do sinfonismo ocidental e na esteira da teoria cinematográfica de S. Eisenstein, pertence ao musicólogo Lev A. Mazel' - Cf. MAZEL', L. A. "Estetika i analyz" / "Estética e análise" in Stat'i pó teorii $i$ analizu muzyki / Ensaios em teoria e análise musical, Moscou: Sovetskij kompozitor, 1982, p. 3-54.
} 
caracterizam Ariadne, as ninfas, os delfins, as cortesãs, as Esmeralda, as mães arcaicas.

$\mathrm{Na}$ interação destes dois princípios a obra se constrói como "organismo vivo" (MAZEL', 1982, p. 24), concentrado carregado de energia corporal, intelectual e emocional. A descoberta artística de Dionysos de Rihm consiste precisamente nesta interação particularmente eficaz destas duas linhas de força de sua estratégia composicional que conferem à obra - dir-se-ia, segundo os preceitos de Nietzsche - mais energia, mais movimento, mais vida. Elas regem a constituição de todas as cenas, bem como a elaboração de todos os personagens neste fluxo relativamente livre de uma "tematização da imaginação"24 (RIHM, 2002b, p. 53) que resulta na música-teatro.

\section{Uma composição "vegetativa"}

Rihm fala freqüentemente de "composição vegetativa" (Ibid., p. 57) e compara seu trabalho de elaboração da matéria musical ao crescimento das heras, das plantas, dos emaranhados vegetais (Gewächsen, Gewirr, Geweben)25. A respeito dos Ditirambos de Dioniso de Nietzsche, ele esclarece: "Após quase 40 anos, estes poemas parecem me acompanhar, espécie de plantas grandiosas e insondáveis que emergem da obscuridade de um mar anamnésico." (RIHM, 2010c, p. 39).

As associações de ordem orgânica ou botânica em filosofia e estética não são novas, é claro: lembremo-nos da "Urpflanze" / "a planta originária" em Johann Wolfgang v. Goethe ${ }^{26}$, ou "der vollkommene Organismus" / "o organismo perfeito" em Arnold Schoenberg. (SCHOENBERG, 1965, p. 74)27 Ou ainda, mais próximos de nós, o rizoma em Gilles Deleuze e Félix Guattari (DELEUZE et GUATTARI, 1980, p. 9-37) e a hera em Rihm. Podemos levar esta metáfora adiante com a figueira banyan de raízes aéreas, cujos galhos parecem viver em reciprocidade direta e permanente com as raízes. E esta metáfora permite

\footnotetext{
24 "Thematisieren von Imagination".

25 Vegetações, excrescências, emaranhados, tecidos.

26 Cf. GOETHE, J. W. v. Die Metamorphose der Pflanzen (1790) und Objekt und Methode der Morphologie (1807).

27 Lembremos que no mesmo almanaque foram publicados pela primeira vez as Herzgewächse / As vegetações do coração, de Schoenberg.
} 
colocar em evidência a possibilidade de variabilidade ou de permutabilidade das funções de diferentes partes do organismo vivo. Rihm escreve: "Em arte, a multiplicidade deve ser a condição primeira da unificação e das novas multiplicações. /.../ A arte cresce /.../ da copa ao tronco e dali às raízes. Ela evolui longe da concreção na profundeza laboriosa." (RIHM, 2002b, p. 58)

As metáforas imagéticas do domínio da botânica que Rihm emprega freqüentemente confirmam sua filiação à grande tradição ocidental, sempre em busca de uma unidade orgânica da obra-total. Mas sua metáfora preferencial da hera dissimula de fato o essencial de sua descoberta formal: a multiplicidade, precisamente, dos materiais utilizados na enunciação musical-cênica e a novidade nos procedimentos formais, Ihe permitem obter, nessas condições de multiplicidade aberta, uma composição sempre orgânica da obra em sua totalidade. Filho do século XX, Rihm busca a multiplicidade teoricamente ilimitada da matéria musical, também com suas remissões a Wagner, Strauss, Bach, Schubert, a si próprio, à valsa, mas sempre visando à coerência e à continuidade dos eventos músico-cênicos na totalidade unificada da obra. Não se trata de referências citacionais estáticas jogando com os contrastes estilísticos, mas da interação metabólica das matérias utilizadas, evocando muito mais a figueira, com suas funções vitais reversíveis, intercambiáveis. A metáfora da hera, em contrapartida, da planta que se propaga de maneira uniforme por todos os lados, desfaz totalmente a multiplicidade e a disparidade dos elementos musicais, essenciais para Rihm em Dionysos. Em sua "fantasia operística", tratase, acima de tudo, de um metabolismo contínuo, de uma reciprocidade permanente dos materiais díspares, o que define a própria especificidade de seu pensamento musical fundado sobre livres-associações. - Lembremo-nos ainda do Lied com acompanhamento de piano Der Wanderer e a textura orquestral de Dionysos que se "entre-enxertam", integrando também o solo de flauta caracterizando Marsyas (3a cena, Innenraum 2 / Espaço interior 2) (RIHM, 20092010, p. 236-241); ou a valsa na $3^{a}$ cena (Innenraum 2), onde as quatro Esmeraldas dançam com a boneca - Ein Gast / Um hóspede (Ibid., p. 248-254); ou ainda o coral para coro misto - Misterioso (in tempo di corale) - com o texto de Nietzsche "Die Wüste wächst! Weh dem, der Wüsten birgt!" / "O deserto cresce! Infeliz daquele que abriga desertos!" ao final de Innenraum 2 da $3^{a}$ cena (Ibid., p. 281-287). 


\section{Der Wanderer / O Errante}

A figura emblemática dissimulada por detrás de N. e seus duplos é, sem dúvida, aquela do Wanderer / o Errante. Não é certamente por acaso que Rihm retoma, no contexto de Dionysos, seu Lied anteriormente escrito Der Wanderer, sobre o poema homônimo do Nietzsche da época de Zaratustra (1883-1885). Não é por acaso que em 1997 ele escreve também um texto sob o título programático "Eine Wanderer-Phantasie"28. No mesmo ano, Rihm transcreve para voz e orquestra o conhecido Lied de Fr. Schubert Der Wanderer (Op. 4/1, D 489, 1816) sobre o texto de Georg Philipp Schmidt von Lübeck. O viajante errante é para ele a personificação da viagem interna, da "divagação interior"29 (RIHM, 2002c, p. 87), do comportamento do pensador/compositor sobre a cena de sua músicateatro. A fantasia operística é em fato constituída de cenas e de ditirambos pensados como representações músico-cênicas dos espaços interiores destas divagações internas, nas quais seguimos os movimentos associativos do pensamento. O Errante, como todos os personagens em Dionysos, não é um personagem histórico ou psicológico. Ele é "presença, movimento incorporado do pensamento"30 (Ibid., p. 88), "homem de aqui e agora. Totalmente não teleológico. Na verdade, ele é intrinsecamente sem meta." ${ }^{31}$ (Ibid., p. 87) Ele é "o representante da fantasia em seu caminho"32 (Ibid., p. 90). E a música sobretudo a de Rihm - é sempre caminho, fluxo, fluir de eventos seguindo livremente os movimentos freqüentemente impulsivos do pensamento.

O errante, assim como o filósofo, o poeta, o louco e/ou o compositor - é "exposto sem defesa à realidade"33 (Ibid., p. 91) "A cabeça do errante fica inclinada para a frente. Ele se deixa penetrar pela imagem do caminho, ele come

\footnotetext{
28 Este texto está publicado em Offene Enden, 2002, pp. 87-91.

29 "Inneres Schweifen".

30 "Gegenwart, inkorporierte Bewegung des Denkens".

31 "Mensch des Hier und Jetzt. Gänzlich unteleologisch. Eigentlich ist er der genuin ziellose."

32 "Er ist der Stellvertreter der Phantasie auf dem Weg." "Weg, fluss, vergehendes Erignis.".

33 "Ungeschützt der Wirklichkeit ausgesetzt".
} 
o caminho com os olhos."34 Ao final da fantasia operística de Rihm, todos os participantes que efetuaram o caminho de N., se inclinam "muito calmamente em direção" ao público35 (RIHM, 2009-2010, p. 369): são viajantes errantes já tendo percorrido um caminho, assim como nós espectadores na sala de concerto. O gesto modesto do corpo inclinado para frente é o emblema da errância e, simultaneamente, um convite a novas viagens: nos espaços interiores já apresentados da fantasia operística que fazem rizoma, se enxertam com os nossos.

Dionysos de Rihm é uma obra forte que apresenta os movimentos do pensamento com os meios da música-teatro. Filho de sua época, inventando a música após o dodecafonismo e a vanguarda serial dos anos 50-60 do século XX e contemporâneo da corrente espectral dos anos 70-80 e após, Rihm sempre compôs sem sistema rígido, com um único método - sua própria intuição e sua própria vontade de compositor. "É uma verdade de la Palisse ${ }^{36}$, porém com muitas conseqüências, se pensarmos quanto tempo precioso foi gasto na loucura, inventar um método, nada mais que um método, e para compor através dele!" - indigna-se Rihm (RIHM, 2002d, p. 97). Neste sentido, ele é também nietzscheano: Lembremos Nietzsche: "Desconfio de todos os fazedores de sistemas e me afasto de seu caminho. O espírito de sistema é uma falta de probidade." (NIETZSCHE, 1980, p. 376; 1974, p. 15)

Podemos duvidar de que Nietzsche teria apreciado a assimilação de Dioniso ao Crucificado e a remissão explícita ao Cristianismo com a imagem cênica da Pietà na Quarta cena de Dionysos. É verdade, a Pele (de Marsyas, N.) cai por terra dos joelhos da Virgem ${ }^{37}$ (RIHM, 2009-2010, p. 368). É verdade, escutamos várias

\footnotetext{
34 "Der Kopf des Wanderers bleibt geneigt. Er Lässt das Bild des Weges in sich ein, er isst den Weg durch seinen Blick."

35 Na última marcação de palco na partitura de Dionysos, lê-se: "Im rasch einbrechenden Dunkel sieht man gerade noch, dass sich alle auf der Bühne versammelten Figuren und Gestalten sehrt ruhig zum Publikum hin verneigen.".

${ }^{36}$ Nota do tradutor: "Verdade de la Palisse" ou "de la Palice", ou ainda "lapalissada" / "lapaliçada" é algo que de tão evidente se torna ridículo. Jacques de la Palisse (1470-1525) foi um dos mais brilhantes marechais franceses de todos os tempos. Uma canção muito popular em sua homenagem trazia o seguinte verso: "Un quart d'heure avant sa mort il était encore en vie". Essa verdade, extremamente ingênua, foi então injustamente atribuída ao próprio La Palisse, dando origem à expressão. (Verbete "La Palisse", Dictionnaire universel des noms propres Le Petit Robert 2, Paris, 1990.

37 Ao final "fällt Die Haut aus der Pietà-Position herab auf den Boden".
} 
vezes ao final da Terceira cena: "Deus como cordeiro... dilacerar deus no homem e rir, rir..." (Ibid., p. 352-354) 38 . Mas a imagem da Pietà é demasiado forte e carregada de sentido para ser colocada em questão. Rihm permanece cristão. Lembremos que Nietzsche terminava Ecce Homo pelas frases: "Compreenderamme? - Dioniso contra o Crucificado..."39 (NIETZSCHE, 1977/2012, p. 358369; Id., 1980, p. 196) E ainda: "A cegueira diante do Cristianismo é o crime por excelência - um crime contra a vida... O cristão foi até aqui "o ser moral" por definição, um curiosum sem igual - e, enquanto "ser moral", o mais absurdo, mais mentiroso, mais vaidoso, mais superficial, mais nocivo para si mesmo que o pior contemptor que a humanidade seria capaz de sonhar." 40 (Ibid., 1977/2012, p. $348-351 ; 1980$, p. 194)

O Crucificado, segundo Nietzsche, gera luto e melancolia, lágrimas e sofrimentos, enquanto Dioniso traz explosão de alegria, dança e riso. "A descoberta da moral cristã, eis um evento histórico sem precedente, uma verdadeira catástrofe." 41 - escrevia Nietzsche (Ibid., 1977/2012, p. 354-355; 1980, p.195). Após mais de dois milênios de Cristianismo, o compositor Rihm procura conciliar Dioniso e o Cristo, e não tem nem a intenção, nem a possibilidade de em sua arte continuar o debate sobre a moral cristã. Mas esquecendo o propósito de Nietzsche "Dioniso contra o Crucificado", o compositor certamente apropriou-se de muitas idéias importantes do filósofo: a idéia da liberdade, da criatividade corporal espontânea sem a força paralisante dos sistemas organizadores, a idéia dos movimentos do pensamento ilimitado em permanente afirmação. Nietzsche queria um homem livre, "um homem para o qual, não há nada mais proibido." "Um tal espírito alforriado se coloca no centro do universo com um fatalismo alegre e confiante, com a convicção profunda de que apenas o individual é condenável, mas que tudo será salvo e reconciliado na Totalidade, - ele não diz mais não... Mas uma tal fé é a mais

\footnotetext{
38 "Gott als Schaff... den Gott zerreissen im Menschen und lachen, lachen...".

39 "Hat man mich verstanden? - Dionysos gegen den Gekreuzigten...".

40 "Die Blindheit vor dem Christentum ist das Verbrechen par excellence - das Verbrechen am Leben... / Der Christ war bisher das "moralische Wesen", ein Curiosum ohne gleichen - und, als "moralisches Wesen", absurder, verlogner, eitler, leichtfertiger, sich selber nachteiliger, als auch der grösste Verächter der Menschheit es sich träumen lassen könnte." Nesse contexto, "leichtfertiger" seria melhor traduzido por "desmiolado" e não por "superficial". - IS.

41 "Die Entdeckung der christlichen Moral ist ein Ereignis, das nicht seinesgleichen hat, eine wirkliche Katastrophe."
} 
elevada de todas as possíveis: eu a batizei com o nome de Dioniso." ${ }^{42}$ (NIETZSCHE, 1974, p. 94; 1980, p. 424) - Daí também, certamente, o título da fantasia operística de Rihm.

A linguagem múltipla da obra de Rihm traduz o comportamento da psique humana que cada um pode explorar individualmente, segundo sua própria sensibilidade e sua própria cultura. O espectador se encontra localizado no cérebro do artista, do "pensador em cena"43 / do "pensador em música-teatro", nos meandros de sua fantasia, de seus espaços internos variáveis, que são todos, reiteramos, uma linguagem do corpo. A obra em cenas e ditirambos de Rihm demanda do espectador uma nova e atenta escuta: ela repousa sobre uma abertura total para as errâncias do pensamento e sobre uma reflexão ativa e contínua sobre os personagens variáveis e as situações flutuantes. "Eu penso que a compreensão da música, é uma abertura infinita. - escreve Rihm. - Nós compreendemos a música na medida em que nos abrimos mais e mais, até a possibilidade de desaparecimento." 44 (RIHM, 2010b, p. 20) A fantasia operística Dionysos de Rihm nos convida a essa nova experiência com a obra de arte: a experiência do errante no interior dos espaços múltiplos e movediços em busca da sua e da nossa verdade.

\footnotetext{
42 "...ein Mensch, für den es nichts verbotenes mehr gibt. Ein solcher freigewordener Geist steht mit einem freudigen und vertrauenden Fatalismus mitten im All, im Glauben, dass nur das einzelne verwerflich ist, dass im ganzen sich alles erlöst und bejaht - er verneint nicht mehr. /.../ Ein solcher Glaube ist der höchste aller möglichen Glauben: ich habe ihn auf den Namen des Dionysos getauft."

43 Cf. SLOTERDIJK , P. Der Denker auf der Buhne / Nietzsches Materialismus, Frankfurt am Main: Suhrkamp, 1986.

44 "Ich glaube, dass das Verstehen von Musik ein unabschliessbares Öffnen ist. Wir verstehen Musik, indem wir uns immer weiter öffnen, bis zur Möglichkeit des Verschwindens."
} 


\section{Referências}

DELEUZE, G.; GUATTARI, F. Rhizome. In: Mille plateaux, Paris: Ed. de Minuit, 1980

MAZEL', L. A. Estetika i analyz. In: Stat'i pó teorii i analizu muzyki, Moscou: Sovetskij kompozitor, 1982.

NIETSZCHE, F. Gedichte, Stuttgart: Reklam, 2010. . Götzen-Dämmerung oder Wie man mit dem Hammer philosophiert, § 26. In: Werke in vier Bänden, Band 4, "Das Bergland-Buch", Salzburg, 1980.

Gallimard, 1974.

Crépuscule des idoles, trad. J. -Cl. Hémery, Folio/Essais, Paris:

. Ecce Homo, trad. J. -Cl. Lémery, Paris: Gallimard, 1977/2012.

. Ecce Homo, In: Werke in vier Bände, Band 1, Caesar Verlag, Wien / das Bergland Buch". Salzburg, 1980.

RIHM, W. Einige Gedanken zur Karlsruher Uraufführung der Zweiten Abgesangsszene. In: Ausgesprochen, Schriften und Gespräche, Band 2, Winterthur: Amadeus, 1997 Hanser, 2002a.

Phantasien zur Oper. In: Offene Enden, München, Wien: Akzente . Musikalische Freiheit. In: Offene Enden, München, Wien: Akzente Hanser, 2002b. Hanser, 2002c.

Eine Wanderer-Phantasie. In: Offene Enden, München, Wien: Akzente

. Dichterischer Text und musikalischer Kontext. In: Offene Enden, München, Wien: Akzente Hanser, 2002d.

Dionysos, Szenen und Dithyramben nach Texten von Freidrich Nietzsche, Libretto vom Komponisten, Wien: Universal Edition, 2009-2010.

Ich will nichts erklären, Entrevista com W. Schreiber e B. Ehrhardt em relação à montagem de Dionysos em Salzburg em 27.7.2010. In

Süddeutsche Zeitung Munich, 2010a.

. Musik ist wohl nur in der Form der Hingabe erfahrbar / Ein Gespräch mit Max Nyffeler, In: W. Rihm - Dionysos, Programmheft, Salzburg: Salzburger Festspiele, 2010b.

Festspiele 2010 c.

Dionysos-Notiz, In: Dionysos, Programmheft, Salzburg: Salzburger

SCHOENBERG, A. Das Verhältnis zum Text. In: Der Blaue Reiter (1912), Hrsg. W. Kandinsky, Fr. Marc, München: Piper Verlag, 1965.

SLOTERDIJK, P. Der Denker auf der Bühne / Nietzsches Materialismus, Frankfurt: Suhrkamp 1353, Neue Folge, Band 353, 1986. 